\title{
Supersonic Aerodynamic Characteristics of Blunt Body Trim Tab Configurations
}

\author{
Ashley M. Korzun* , Kelly J. Murphy ${ }^{\dagger}$, and Karl T. Edquist $\ddagger$ \\ NASA Langley Research Center, Hampton,VA, 23681, USA
}

\begin{abstract}
Trim tabs are aerodynamic control surfaces that can allow an entry vehicle to meet aerodynamic performance requirements while reducing or eliminating the use of ballast mass and providing a capability to modulate the lift-to-drag ratio during entry. Force and moment data were obtained on 38 unique, blunt body trim tab configurations in the NASA Langley Research Center Unitary Plan Wind Tunnel. The data were used to parametrically assess the supersonic aerodynamic performance of trim tabs and to understand the influence of tab area, cant angle, and aspect ratio. Across the range of conditions tested (Mach numbers of 2.5, 3.5, and 4.5; angles of attack from $-4^{\circ}$ to $+20^{\circ}$; angles of sideslip from $0^{\circ}$ to $+8^{\circ}$ ), the effects of varying tab area and tab cant angle were found to be much more significant than effects from varying tab aspect ratio. Aerodynamic characteristics exhibited variation with Mach number and forebody geometry over the range of conditions tested. Overall, the results demonstrate that trim tabs are a viable approach to satisfy aerodynamic performance requirements of blunt body entry vehicles with minimal ballast mass. For a $70^{\circ}$ sphere-cone, a tab with $3 \%$ area of the forebody and canted approximately $35^{\circ}$ with no ballast mass was found to give the same trim aerodynamics as a baseline model with ballast mass that was $5 \%$ of the total entry mass.
\end{abstract}

\section{Nomenclature}

$\begin{array}{ll}A & \text { Area, } \mathrm{m}^{2} \\ A F & \text { Axial force, } \mathrm{N} \\ C & \text { Coefficient value } \\ D & \text { Diameter, } \mathrm{m} \\ L / D & \text { Lift-to-drag ratio } \\ M & \text { Mach number } \\ m & \text { Mass, } \mathrm{kg} \\ N F & \text { Normal force, } \mathrm{N} \\ P M & \text { Pitching moment, } \mathrm{N}-\mathrm{m} \\ p & \text { Pressure, } \mathrm{N} / \mathrm{m}^{2} \\ q & \text { Dynamic pressure, } \mathrm{N} / \mathrm{m}^{2} \\ R M & \text { Rolling moment, N-m } \\ R e & \text { Reynolds number per foot } \\ S F & \text { Side force, } \mathrm{N} \\ T & \text { Temperature, } \mathrm{K} \\ x & \text { Axial location, } \mathrm{m} \\ Y M & \text { Yawing moment, } \mathrm{N}-\mathrm{m} \\ z & \text { Radial location, } \mathrm{m}\end{array}$

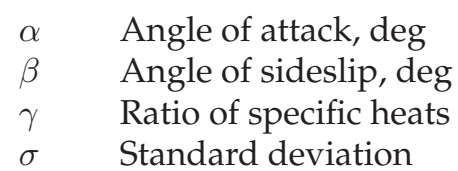

Subscript

$A \quad$ Axial force

$C G \quad$ Center of gravity

$D \quad$ Drag force

$L \quad$ Lift force

$l \quad$ Rolling moment

$m \quad$ Pitching moment

$N \quad$ Normal force

$n \quad$ Yawing moment

ref Aerodynamic reference

trim Aerodynamic trim condition

$Y \quad$ Side force

$0 \quad$ Total condition

$\infty \quad$ Freestream condition

\footnotetext{
*Aerospace Engineer, Atmospheric Flight and Entry Systems Branch, M/S 489, ashley.m.korzun@nasa.gov, AIAA Member.

$\dagger$ Aerospace Engineer, Aerothermodynamics Branch, M/S 408A, kelly.j.murphy@nasa.gov.

${ }_{\ddagger}^{\ddagger}$ Aerospace Engineer, Atmospheric Flight and Entry Systems Branch, M/S 489, karl.t.edquist@nasa.gov, Senior AIAA Member.
} 


\section{Introduction}

Achieving precision landing, accessing landing sites at higher surface elevations, and increasing payload mass to the surface on Mars requires the ability to generate aerodynamic lift. ${ }^{1}$ To date, only the Viking landers (Viking I and Viking II) and Mars Science Laboratory (MSL) were designed to fly with a non-zero angle of attack. All three vehicles provided aerodynamic lift with an axisymmetric capsule configuration through an offset of the vehicle's center of gravity (CG) in the radial direction. The Viking landers' radial CG offset $\left(L / D=-0.18, \alpha_{\text {trim }}=11^{\circ}\right)$ was produced through a combination of the stowed lander's position and configuration within the aeroshell and ballast mass.,3 Unlike the Viking landers, payload packaging could not provide the required CG offset for MSL $\left(L / D=-0.24, \alpha_{\text {trim }}=16^{\circ}\right)$, and six tungsten entry ballast masses totaling $174 \mathrm{~kg}$ were used to achieve the required aerodynamic performance. ${ }^{4}$ For comparison, the mass of each Mars Exploration Rover was $174 \mathrm{~kg}{ }^{4}$ These masses were then ejected to re-trim the vehicle to zero degrees angle of attack prior to parachute deployment. An additional $153.5 \mathrm{~kg}$ of ballast mass were required to balance the MSL cruise stage, jettisoned prior to entry to trim the vehicle to $\alpha=16^{\circ}$. The entry ballast mass system alone exceeded 30\% of the payload mass for MSL. Providing similar or improved aerodynamic lift performance with less mass reduces constraints on the entry, descent, and landing (EDL) design space and allows trading of payload mass for landing site elevation and/or landing accuracy.

Trim tabs are deployable, aerodynamic control surfaces capable of trimming a vehicle to a non-zero angle of attack without requiring a radial CG offset. In addition to their potential as low-mass devices, trim tabs may provide similar or better aerodynamic performance across a broad range of Mach numbers than an axisymmetric capsule with a CG offset, as well as the ability to modulate $L / D$ by varying tab configuration. ${ }^{5,6}$ Figure 1 illustrates a trim tab concept and an entry ballast mass concept for robotic Mars EDL. A single trim tab provides uni-directional pitch control, while two or more trim tabs can provide both pitch and yaw control through alteration of $L / D$ magnitude and direction. Yaw control with additional trim tabs may provide more responsive cross-range maneuvering than a propulsive reaction control system through better aerodynamic performance across a broad range of Mach numbers and no interference with the capsule's wake flow.

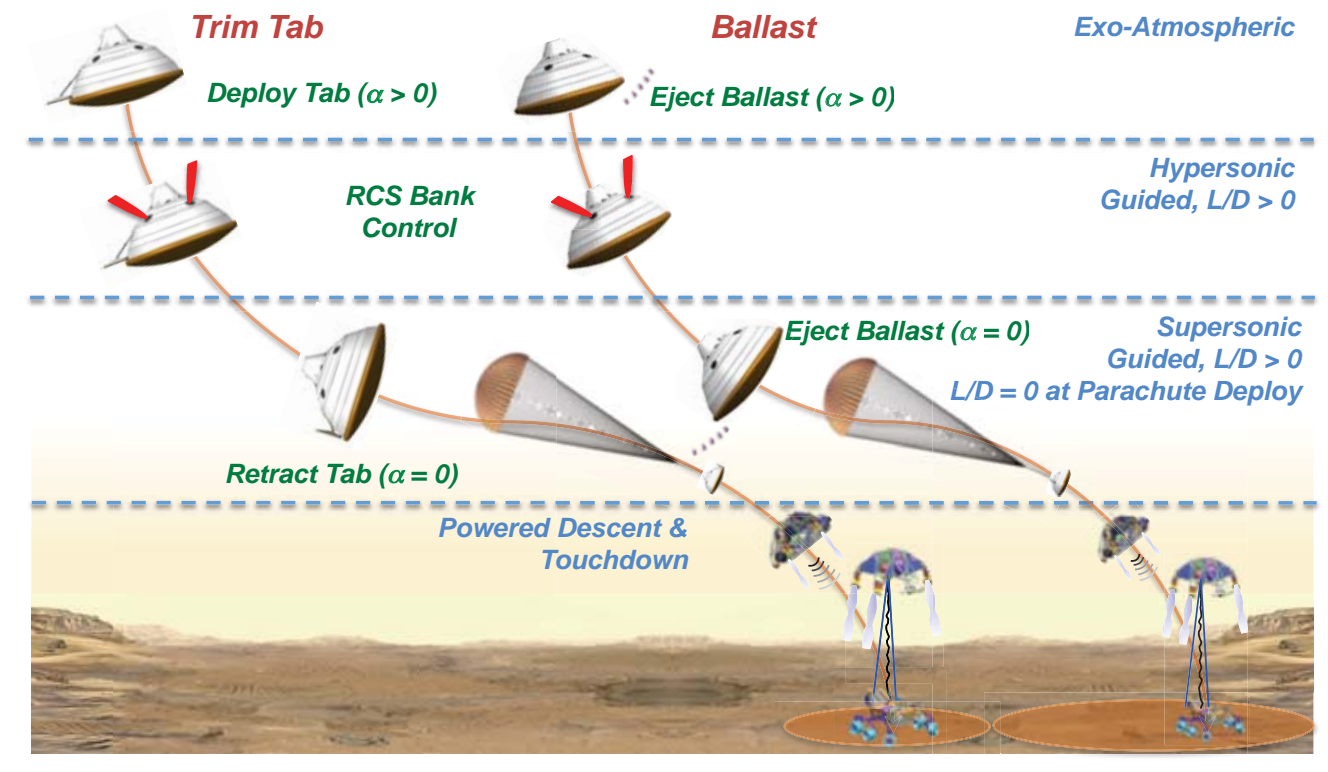

Figure 1. Concepts for robotic Mars EDL using a trim tab or entry ballast mass.

Experimental investigations of trim tab configurations occurred as early as 1961 for Mercury-type and Apollo-type entry capsules. ${ }^{7-9}$ More recent work has examined the feasibility of trim tabs for robotic Mars lander missions through systems analysis, ${ }^{6,10-12}$ wind tunnel testing, ${ }^{5,13}$ and computational aerodynamic analysis. ${ }^{5,13-15}$ These systems analysis efforts have demonstrated that trim tabs provide increased payload mass and access to higher surface elevations in the southern Martian hemisphere using a robotic-scale EDL architecture with a rigid (heritage) aeroshell. 
NASA's EDL Systems Analysis effort examined the use of a single trim tab prior to deployment of a supersonic ringsail parachute to improve the entry performance of MSL as one of eight different technology sets (other technologies considered included inflatable and deployable supersonic aerodynamic decelerators, lifting capsule configurations with ballast, and improved supersonic and subsonic parachutes). ${ }^{6}$ Constraining the launch mass to the capability of an Atlas V $551(5130 \mathrm{~kg})$, the study found the technology set utilizing the trim tab to have a landed mass more than $150 \mathrm{~kg}$ greater than the next closest alternative, delivering $1462 \mathrm{~kg}$ of payload to $+1.83 \mathrm{~km}$ elevation (relative to the Mars Orbiter Laser Altimeter (MOLA) reference areoid). The increased payload mass was a direct result of using a trim tab in place of entry ballast for the guided, hypersonic phase of the trajectory. With a conservative mass estimate, the trim tab system mass was approximately $1 / 10^{t h}$ of the entry ballast mass required to achieved the same $L / D .{ }^{6}$ Optimized to land at $0 \mathrm{~km}$ elevation using the existing MSL supersonic parachute, the trim tab architecture still demonstrated a significant performance benefit, increasing payload mass to the surface by more than $200 \mathrm{~kg}\left(m_{\text {payload, trim tab }}=1132 \mathrm{~kg}, m_{\text {payload }, M S L}=919 \mathrm{~kg}\right)^{6}{ }^{6}$

A preliminary design study of a 2018 Mars mission considered use of a trim tab in place of entry ballast mass to increase parachute deployment altitude, increase entry mass, and reduce the error ellipse at parachute deployment for an MSL-derived EDL system. ${ }^{12}$ Under the specific constraints on the analysis (see Ref. ${ }^{12}$ ), payload mass can be increased by using a trim tab for entry masses below approximately 3230 $\mathrm{kg}$ (MSL entry mass: approximately $3300 \mathrm{~kg}$ ) in targeting the maximum parachute deployment altitude for a given entry mass and $L / D$.

Each of these analyses assumed a fixed trim tab design, varying $L / D$ by varying tab cant angle. Highfidelity aerodynamic analyses were not used to generate aerodynamic and aerothermodynamic databases, primarily due to a lack of parametric experimental data with which to anchor and validate computational tools. Recent wind tunnel testing has partially amended this deficiency by providing a parametric data set for trim tabs at supersonic conditions.

This paper uses force and moment data from Test 1875 - Trim Tab Parametric Models (TTPM), a test completed in May 2012 in the NASA Langley Research Center (LaRC) Unitary Plan Wind Tunnel (UPWT), to parametrically assess the supersonic aerodynamic characteristics of blunt body configurations with trim tabs and to understand the significance of tab area, tab cant angle, and tab aspect ratio. Section II provides a brief overview of the wind tunnel test and parametric data set. Section III describes the general analysis approach, and Section IV presents analysis results emphasizing parametric trends and aerodynamic trim characteristics. Section $V$ discusses the implications of trim tab performance for entry vehicle design and examines the effects of tab area and tab cant angle for mission-relevant aerodynamic performance.

\section{Test Summary}

The objective of TTPM wind tunnel testing was to support supersonic aerodynamic database development for trim tab configurations. Force and moment testing was completed with a six-component straingage balance for 38 unique blunt body trim tab configurations in the NASA LaRC UPWT. Test conditions spanned freestream Mach numbers of 2.5,3.5, and 4.5 at $R e_{\infty}=1 \times 10^{6}$, with a limited number of $M_{\infty}=4.5$ runs at $R e_{\infty}=1.5 \times 10^{6}$. Angle of attack ranged from $-4^{\circ}$ to $+20^{\circ}$. Angle of sideslip ranged from $0^{\circ}$ to $+8^{\circ}$ at $\alpha=16^{\circ}$ for all configurations except the $70^{\circ}$ sphere-cone with no tab, which has data for $\beta=-8^{\circ}$ to $+8^{\circ}$ at $\alpha=0^{\circ}$ and $20^{\circ}$. The $\pm 2 \sigma$ uncertainties for the balance data are given in Table 1 .

Figure 2 shows the different trim tab models, and Fig. 3 defines the model geometry. Each model was 6 inches in diameter. All of the sphere-cone forebody geometries had a nose radius of 1.5 inches and a shoulder radius of 0.15 inches, with the exception of one $60^{\circ}$ forebody configuration, which had a nose radius of 0.75 inches. The Apollo forebody geometry had a nose radius of 7.11 inches and a shoulder radius of 0.30 inches. Nineteen models were painted with pressure sensitive paint (PSP) and included reference pressure ports on the forebody and aftbody. Flowfield schlieren images were also taken for each configuration at each $M_{\infty}$ condition. All models were run with a balance shroud only (no backshell); one $70^{\circ}$ sphere-cone model was also run with the MSL aftbody.

The 38 blunt body models encompass four forebody geometries $\left(70^{\circ}, 60^{\circ}\right.$, and $50^{\circ}$ sphere-cones and Apollo), different numbers of tabs $(0,1$, and 2 tabs), three tab areas $(1.5 \%, 3.0 \%$, and $6.0 \%$, relative to the base area of the model), three tab aspect ratios (2:1, 1:2, and 1:1), and different tab cant angles. Tab aspect ratio is defined as the ratio of tab width to tab height. For each forebody geometry, the tab cant angles for configurations with one tab are: parallel to the forebody $\left(0^{\circ}\right.$ cant angle), perpendicular to the body axis $\left(90^{\circ}\right.$ 
- cone half-angle for sphere-cones), and perpendicular to the forebody $\left(90^{\circ}\right.$ cant angle). The $60^{\circ}$ sphere-cone forebody models include a configuration with an additional, intermediate tab cant angle of $60^{\circ}$. Figure 4 shows examples of the different forebody geometries, tab areas, tab aspect ratios, and tab cant angles. A full summary of the tab parameters specific to each configuration is given in Table 2. The trim characteristics given in Table 2 are discussed in Section IV C.

Table 1. Balance uncertainties.

\begin{tabular}{|c|c|c|c|c|c|c|c|}
\hline & NF (lbs) & AF (lbs) & SF (lbs) & PM (in-lbs) & RM (in-lbs) & YM (in-lbs) \\
\hline \multicolumn{2}{|c|}{ Maximum Load } & 100 & 225 & 60 & 150 & 50 & 120 \\
\hline \multicolumn{2}{|c|}{ Accuracy (\%F.S.) } & 0.15 & 0.09 & 0.14 & 0.16 & 0.11 & 0.11 \\
\hline \multicolumn{2}{|c|}{ Accuracy (Load) } & 0.15 & 0.2025 & 0.084 & 0.24 & 0.055 & 0.132 \\
\hline$M_{\infty}$ & $q_{\infty}(\mathrm{psi})$ & $\begin{array}{c}C_{N} \pm 2 \sigma \\
\text { Accuracy }\end{array}$ & $\begin{array}{c}C_{A} \pm 2 \sigma \\
\text { Accuracy }\end{array}$ & $\begin{array}{c}C_{Y} \pm 2 \sigma \\
\text { Accuracy }\end{array}$ & $\begin{array}{c}C_{m} \pm 2 \sigma \\
\text { Accuracy }\end{array}$ & $\begin{array}{c}C_{l} \pm 2 \sigma \\
\text { Accuracy }\end{array}$ & $\begin{array}{c}C_{n} \pm 2 \sigma \\
\text { Accuracy }\end{array}$ \\
\hline 2.5 & 1.42 & \pm 0.0037 & \pm 0.0050 & \pm 0.0021 & \pm 0.0010 & \pm 0.0002 & \pm 0.0005 \\
\hline 3.5 & 1.06 & \pm 0.0050 & \pm 0.0068 & \pm 0.0028 & \pm 0.0013 & \pm 0.0003 & \pm 0.0007 \\
\hline 4.5 & 0.79 & \pm 0.0067 & \pm 0.0090 & \pm 0.0038 & \pm 0.0018 & \pm 0.0004 & \pm 0.0010 \\
\hline
\end{tabular}

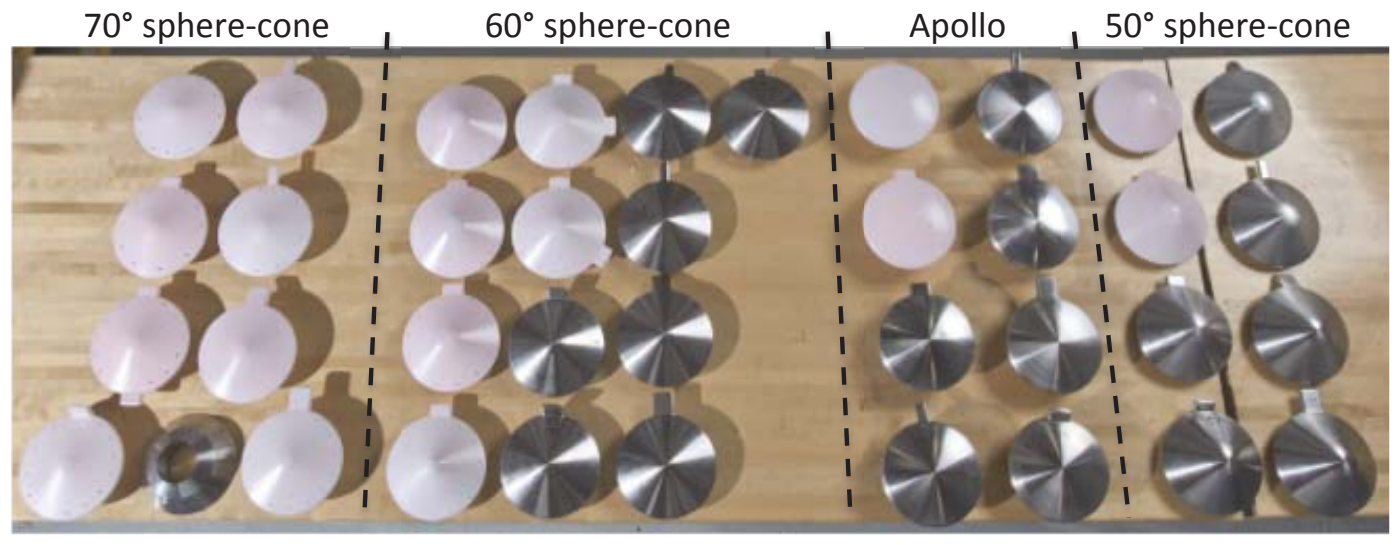

Figure 2. Blunt body trim tabs wind tunnel test models (one model missing from photo) and the MSL aftbody.

The test matrix is non-square with regard to the tab parameters. Tab area and tab aspect ratio effects cannot be fully decoupled, as the moment arm of the tab changes with each of these parameters. Additionally, variation across the full range of tab cant angles $\left(0^{\circ}\right.$ to $\left.90^{\circ}\right)$ is only available for the $3 \%$ area tabs with a 2:1 tab aspect ratio. However, a minimum of two variations in each tab parameter and the no-tab baseline are available for each forebody geometry and $M_{\infty}$ condition. Results from this test are compared with results from similar wind tunnel tests in Section IV. Additional detail on the design and execution of the wind tunnel test can be found in complimentary work by Murphy et al. ${ }^{16}$ 


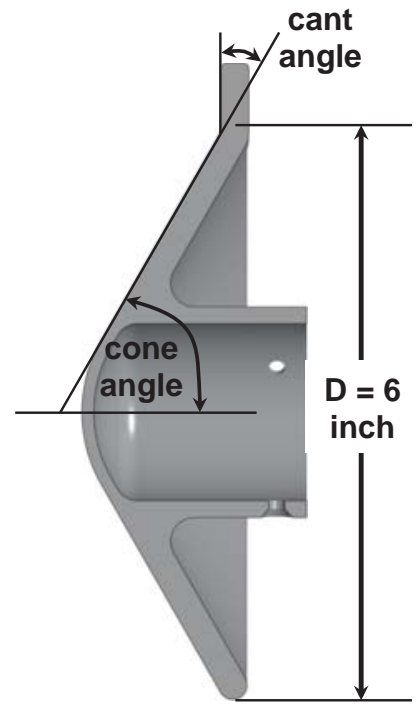

Figure 3. Model geometry (example: $60^{\circ}$ sphere-cone forebody with $30^{\circ}$ tab cant angle).

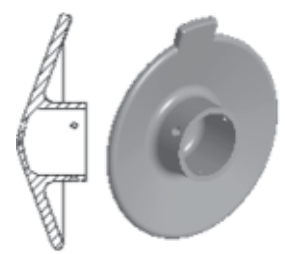

70 deg S-C

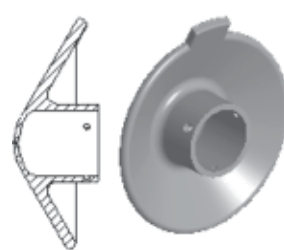

60 deg S-C

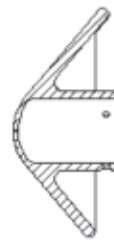

50 deg S-C

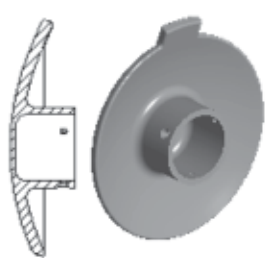

Apollo

(a) Forebody geometries with $0^{\circ}$ tab cant angle
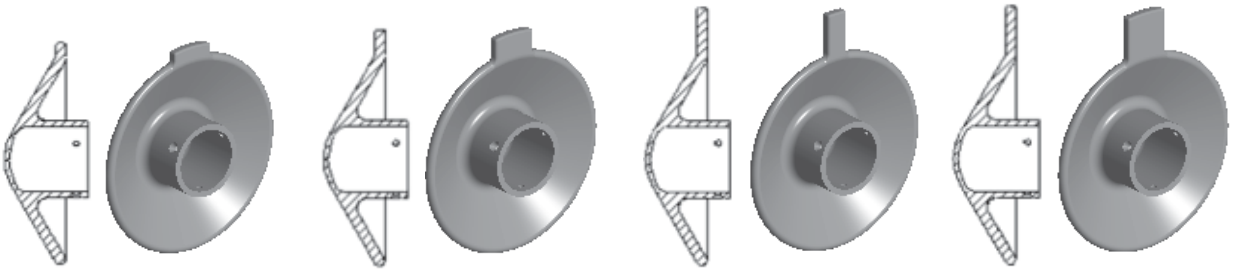

$1.5 \%$ area, $A R=2: 1$

$3 \%$ area, $A R=2: 1$

$3 \%$ area, $A R=1: 2$

$6 \%$ area, $A R=1: 1$

(b) Tab areas and aspect ratios for $60^{\circ}$ forebody

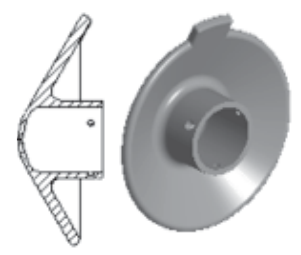

0은

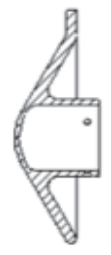

30 은

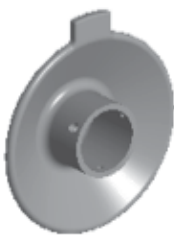

c) Tab cant angles for $60^{\circ}$ forebody

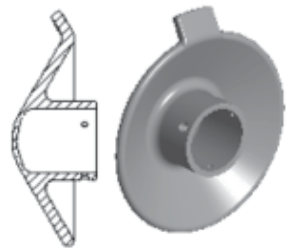

$60^{\circ}$
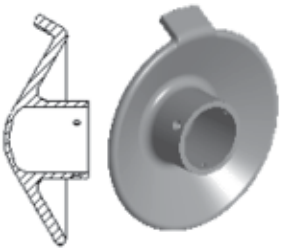

$90^{\circ}$

Figure 4. Examples of forebody geometry, tab area, tab aspect ratio, and tab cant angle. 
Table 2. Summary of all trim tab configurations and trim characteristics. Trim characteristics $\left(\alpha_{\text {trim }}\right.$ and $\left.(L / D)_{\text {trim }}\right)$ assume $x_{C G} / D=0.291$ and $z_{C G} / D=\mathbf{0 . 0}$.

\begin{tabular}{|c|c|c|c|c|c|c|c|}
\hline \multirow[b]{2}{*}{ Forebody } & \multirow[b]{2}{*}{ Aftbody } & \multicolumn{4}{|c|}{ Trim Tab Configuration } & \multicolumn{2}{|c|}{ Trim Characteristics } \\
\hline & & Cant Angle & Area & Aspect Ratio & Location(s) & $\alpha_{\text {trim }}$ & $(L / D)_{\text {trim }}$ \\
\hline \multirow[t]{10}{*}{$70^{\circ}$} & Shroud only & none & none & none & none & -0.297 & 0.005 \\
\hline & & $0^{\circ}$ & $3 \%$ & $(2: 1)$ & $0^{\circ}$ & 8.846 & -0.149 \\
\hline & & $20^{\circ}$ & & & $0^{\circ}$ & 14.854 & -0.240 \\
\hline & & $20^{\circ}$ & & & $0^{\circ}, 180^{\circ}$ & -1.133 & 0.022 \\
\hline & & $90^{\circ}$ & & & $0^{\circ}$ & 25.803 & -0.389 \\
\hline & & $0^{\circ}$ & & $(1: 2)$ & $0^{\circ}$ & 8.238 & -0.138 \\
\hline & & $20^{\circ}$ & & & $0^{\circ}$ & 14.678 & -0.239 \\
\hline & & $0^{\circ}$ & $6 \%$ & $(1: 1)$ & $0^{\circ}$ & 16.918 & -0.287 \\
\hline & & $20^{\circ}$ & & & $0^{\circ}$ & 28.844 & -0.468 \\
\hline & MSL & $20^{\circ}$ & & & $0^{\circ}$ & 28.844 & -0.468 \\
\hline \multirow[t]{12}{*}{$60^{\circ}$} & Shroud only & none & none & none & none & 0.844 & -0.016 \\
\hline & & $0^{\circ}$ & $3 \%$ & $(2: 1)$ & $0^{\circ}$ & 7.587 & -0.120 \\
\hline & & $30^{\circ}$ & & & $0^{\circ}$ & 14.936 & -0.217 \\
\hline & & $30^{\circ}$ & & & $0^{\circ}, 90^{\circ}$ & 14.971 & -0.218 \\
\hline & & $30^{\circ}$ & & & $0^{\circ}, 120^{\circ}$ & 9.517 & -0.143 \\
\hline & & $60^{\circ}$ & & & $0^{\circ}$ & 19.940 & -0.275 \\
\hline & & $90^{\circ}$ & & & $0^{\circ}$ & 19.670 & -0.256 \\
\hline & & $0^{\circ}$ & & $(1: 2)$ & $0^{\circ}$ & 7.122 & -0.113 \\
\hline & & $30^{\circ}$ & & & $0^{\circ}$ & 14.729 & -0.208 \\
\hline & & $0^{\circ}$ & $6 \%$ & $(1: 1)$ & $0^{\circ}$ & 12.660 & -0.195 \\
\hline & & $30^{\circ}$ & & & $0^{\circ}$ & 26.380 & -0.355 \\
\hline & & $30^{\circ}$ & $1.5 \%$ & $(2: 1)$ & $0^{\circ}$ & 7.363 & -0.106 \\
\hline $60^{\circ}$ & ${ }^{*}$ mod. nose & $30^{\circ}$ & $3 \%$ & $(2: 1)$ & $0^{\circ}$ & 14.203 & -0.202 \\
\hline \multirow[t]{8}{*}{$50^{\circ}$} & Shroud only & none & none & none & none & 0.249 & -0.005 \\
\hline & & $0^{\circ}$ & $3 \%$ & $(2: 1)$ & $0^{\circ}$ & 3.171 & -0.037 \\
\hline & & $40^{\circ}$ & & & $0^{\circ}$ & 10.162 & -0.099 \\
\hline & & $90^{\circ}$ & & & $0^{\circ}$ & 11.142 & -0.086 \\
\hline & & $0^{\circ}$ & & $(1: 2)$ & $0^{\circ}$ & 3.016 & -0.035 \\
\hline & & $40^{\circ}$ & & & $0^{\circ}$ & 11.115 & -0.097 \\
\hline & & $0^{\circ}$ & $6 \%$ & $(1: 1)$ & $0^{\circ}$ & 6.621 & -0.073 \\
\hline & & $40^{\circ}$ & & & $0^{\circ}$ & 21.14 & -0.207 \\
\hline \multirow[t]{8}{*}{ Apollo } & Shroud only & none & none & none & none & 0.282 & -0.006 \\
\hline & & $0^{\circ}$ & $3 \%$ & $(2: 1)$ & $0^{\circ}$ & 7.317 & -0.124 \\
\hline & & $23^{\circ}$ & & & $0^{\circ}$ & 13.982 & -0.223 \\
\hline & & $90^{\circ}$ & & & $0^{\circ}$ & 6.704 & -0.113 \\
\hline & & $0^{\circ}$ & & $(1: 2)$ & $0^{\circ}$ & 12.521 & -0.197 \\
\hline & & $23^{\circ}$ & & & $0^{\circ}$ & 13.208 & -0.223 \\
\hline & & $0^{\circ}$ & $6 \%$ & $(1: 1)$ & $0^{\circ}$ & 23.535 & -0.367 \\
\hline & & $23^{\circ}$ & & & $0^{\circ}$ & 22.610 & -0.318 \\
\hline
\end{tabular}




\section{Analysis Approach}

Figure 5 defines the static aerodynamic coefficients for a blunt body at a positive angle of attack. $C_{A}$ $>>C_{N}$ for blunt bodies at small angles of attack (less than $30^{\circ}$ ), resulting in $C_{A}$ driving both $C_{L}$ and $C_{D}$. Note that axial force is in the direction opposite angle of attack; $L / D<0$ for $\alpha>0$. Axial and normal forces (body frame) are related to lift and drag forces (velocity frame) by Eqs. 1 and 2. Counter-clockwise (nose-up) pitching moments are positive.

Continuous $\alpha$ sweep data facilitated data analysis for T1875 by allowing curve fits for force and moment trends to be generated from more than 130 data points for each case. Test data from $\alpha$ pitch/pause and continuous $\alpha$ sweep runs for each configuration and $M_{\infty}$ condition are combined and a quadratic curve fit (least-squares approach) developed for $C_{A}, C_{N}, C_{D}, C_{L}, C_{m, r e f}$, and $L / D$ as functions of $\alpha$. All test data is referenced to the nose of the model. $\mathrm{R}^{2}$ is used to measure the proportion of the total variation in the data explained by the model (here, the quadratic curve fit), where a higher value of $\mathrm{R}^{2}$ indicates a better fit of the data by the model. Calculation of the $\mathrm{R}^{2}$ value for each fit from the sum-squared error and the total sum of squares yields a minimum $\mathrm{R}^{2}$ of 0.96 across all fits, with the majority of the $\mathrm{R}^{2}$ values exceeding 0.99. All subsequent data analysis uses the fitted test data. An example of the fitted data is given in Fig. 6. The small points in Fig. 6 are the continuous $\alpha$ sweep data, and the large points are the data from $\alpha$ and $\beta$ pitch/pause test runs. The solid black line is the fit generated from the continuous and pitch/pause data. The dashed black lines represent $\pm 2 \sigma$ uncertainty on the wind tunnel test data. These uncertainties were given previously in Table 1 and are applicable in Fig. 6 to $C_{A}, C_{N}$, and $C_{m}$.

Equation 3 translates the pitching moment about the nose to a specified CG location $\left(x_{C G} / D, z_{C G} / D\right)$ aft of the nose. The vehicle is statically trimmed when $C_{m, C G}$ is equal to zero; the trim angle of attack is found through interpolation of the test data such that this condition is satisfied. Equation 3 is also used to calculate the CG location required to trim the vehicle at a desired $L / D($ or $\alpha)$. Trim characteristics are calculated for a relevant range of axial CG locations: $0.20 \leq x_{C G} / D \leq 0.35$, measured aft from the nose. For all configurations with a trim tab, the radial CG location is assumed to be $z_{C G} / D=0$. Comparisons are made to MSL aerodynamic performance ${ }^{4}$ using the no-tab baseline configuration for the $70^{\circ}$ sphere-cone, assuming $x_{C G} / D=0.291$ and $z_{C G} / D=-0.021$ trim the vehicle to $\alpha=16^{\circ}\left(L / D=-0.29\right.$ at $M_{\infty}=4.5, L / D=$ -0.24 at hypersonic conditions).

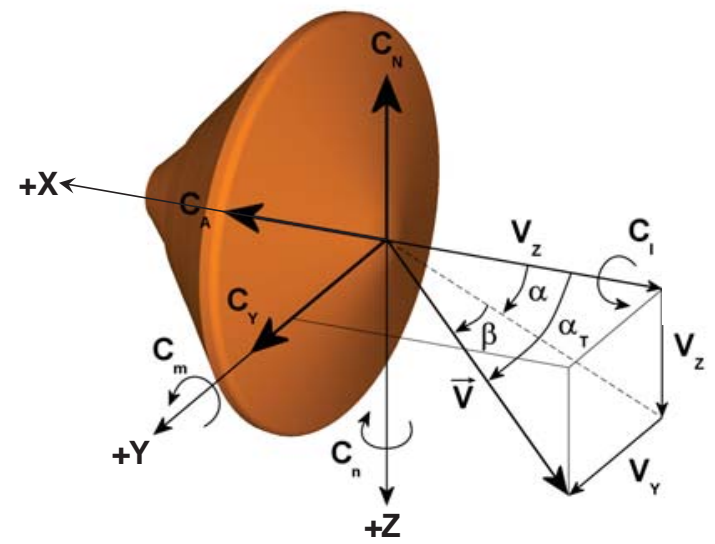

Figure 5. Aerodynamics coordinate system. Counter-clockwise (nose-up) pitching moment about the CG is positive.

$$
\begin{gathered}
C_{L}=C_{N} \cos \alpha-C_{A} \sin \alpha \\
C_{D}=C_{N} \sin \alpha+C_{A} \cos \alpha \\
C_{m, C G}=C_{m, r e f}+C_{N}\left(\frac{x_{C G}-x_{r e f}}{D}\right)-C_{A}\left(\frac{z_{C G}-z_{r e f}}{D}\right)
\end{gathered}
$$



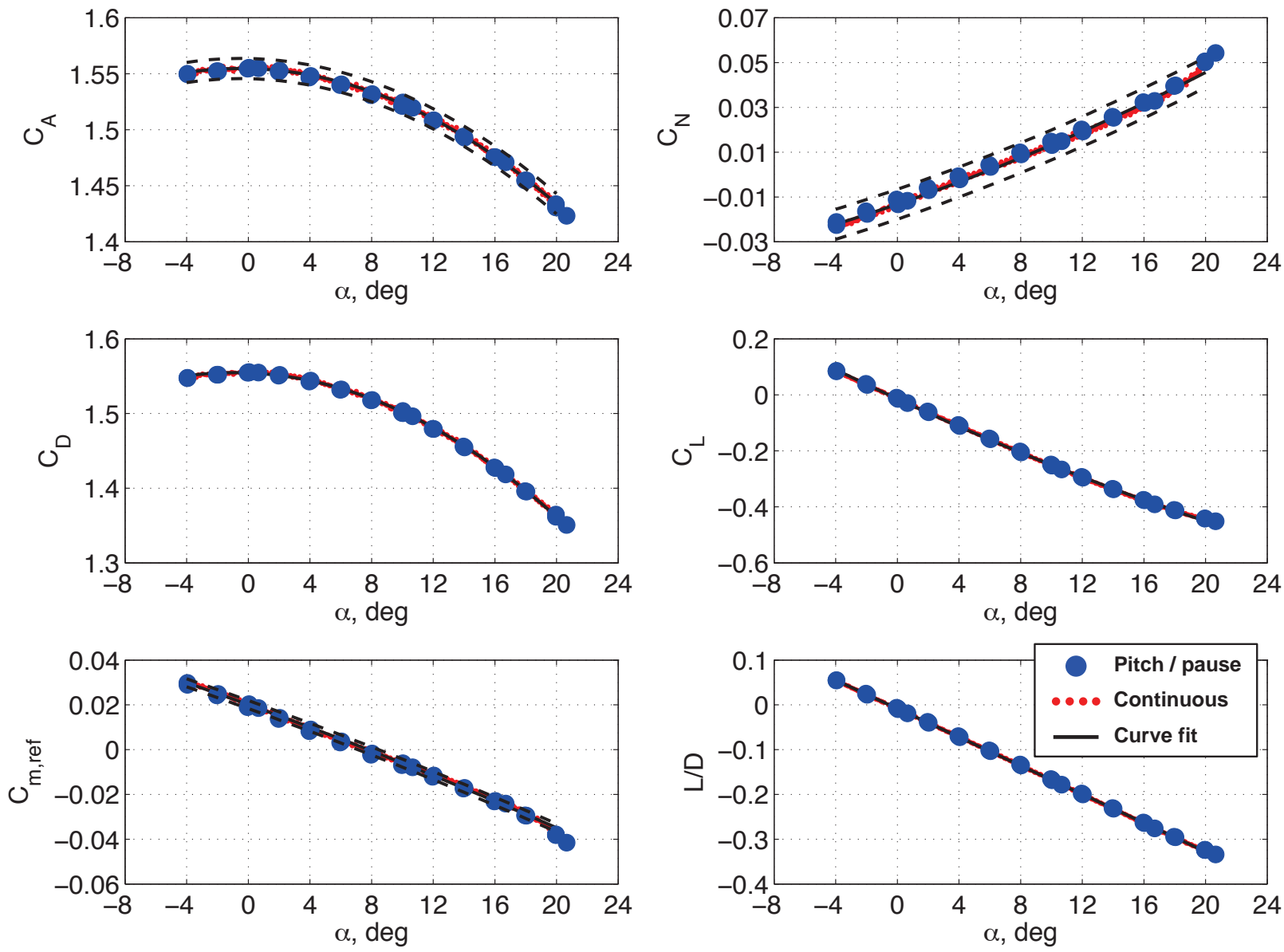

Figure 6. Example of test data and quadratic curve fits $\left(70^{\circ}\right.$ sphere-cone forebody, $1 \mathrm{tab}, 3 \%$ area, $2: 1$ aspect ratio, $0^{\circ}$ cant angle $)$ at $M_{\infty}=4.5$. Dashed lines represent $\pm 2 \sigma$ uncertainty on the wind tunnel balance data.

Trim tabs provide aerodynamic lift without requiring a radial CG offset. The effectiveness of each trim tab configuration is subsequently evaluated by calculating the radial CG offset required for the no-tab configuration with the same forebody geometry. Aerodynamic performance is also assessed using increments in force and moment coefficients, relative to the baseline (no-tab) configurations for each forebody geometry.

\section{Results}

This section presents the results of post-test data analysis. Comparisons are made between T1875 data and similar wind tunnel test data for $70^{\circ}$ sphere-cone forebodies to verify force and moment trends with angle of attack. Using the fitted test data, comparisons are made between different forebody geometries, number of tabs, and tab parameters. Aerodynamic trim characteristics are calculated for each trim tab configuration. The relative significance of tab area, tab cant angle, and tab aspect ratio is demonstrated using the set of pairwise comparisons afforded by the test matrix. The relationship between tab area and aerodynamic performance is also examined in this section. Design implications specific to tab area and tab cant angle are discussed in the following section.

\section{A. Comparison with Other $70^{\circ}$ Sphere-Cone Data Sets}

Figure 7 compares the baseline (no-tab) data from T1875 with other $70^{\circ}$ sphere-cone data sets as an initial check of the test data. These data sets are: T1735 - Mars Smart Lander aerodynamic testing, ${ }^{13}$ Viking 
aerodynamic testing, ${ }^{17}$ and MSL aerodynamic testing. ${ }^{4}$ Conditions vary across these tests, namely $R e_{\infty}$, $M_{\infty}, \alpha$, and the configuration of the backshell (no backshell, flat face, biconic, and MSL, respectively).

Data from all of the tests in Fig. 7 show higher order behavior in $C_{A}$ at lower Mach numbers (below Mach 2.7) and more quadratic behavior at higher Mach numbers (above Mach 2.7). The $C_{N}$ data for cases with a backshell (T1735 and MSL) exhibit non-monotonically increasing behavior with increasing angle of attack between $\alpha=-5^{\circ}$ and $+5^{\circ}$ at Mach numbers of 2.5 and below. This behavior is not seen under any conditions in the $C_{N}$ data from T1875 and the Viking test, both of which used a balance shroud and no backshell. Overall, the trends in $C_{A}$ and $C_{N}$ for the T1875 baseline configuration agree well with data from other tests of the same forebody geometry.
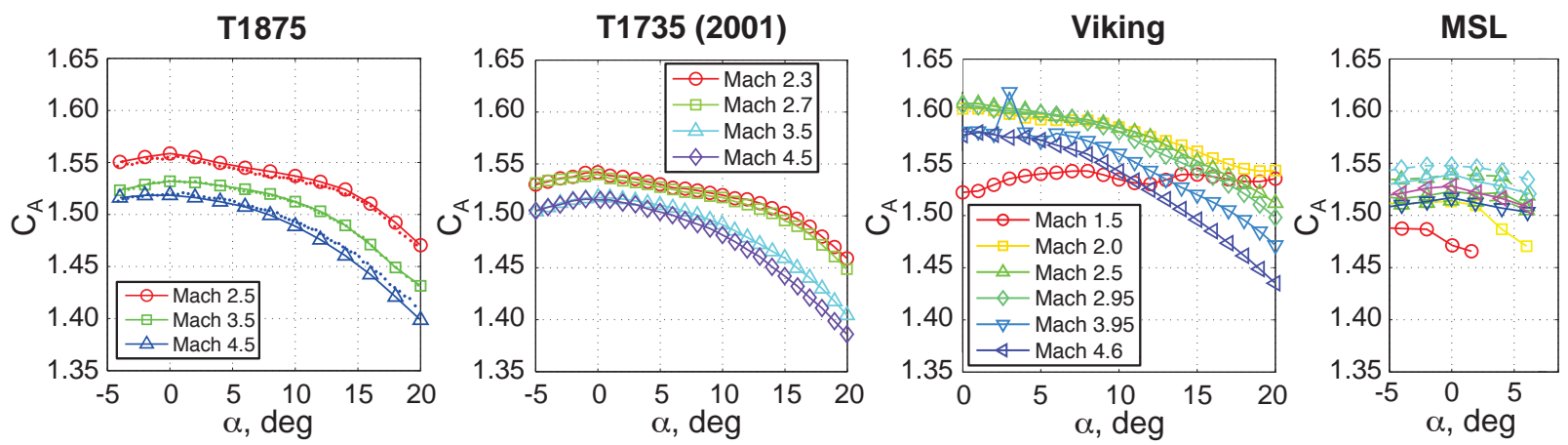

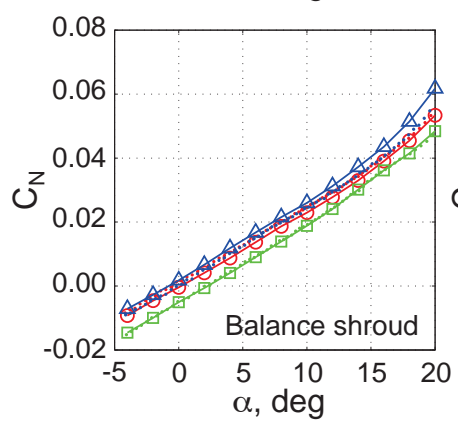

$\operatorname{Re}_{\infty}=1 \times 10^{6}$

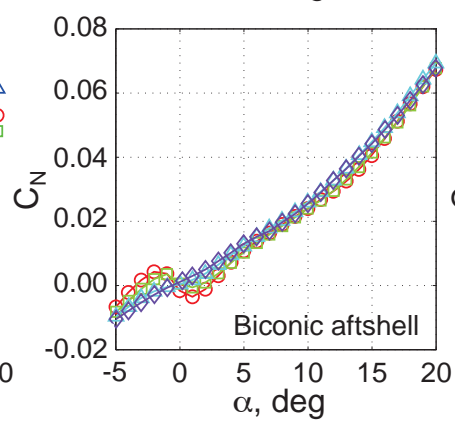

$\mathrm{Re}_{\infty}=2 \times 10^{6}$

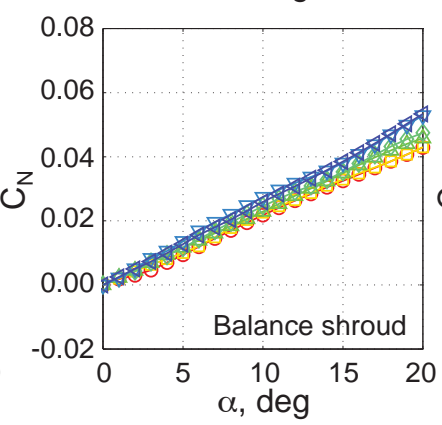

$\operatorname{Re}_{\infty}=1 \times 10^{6}$

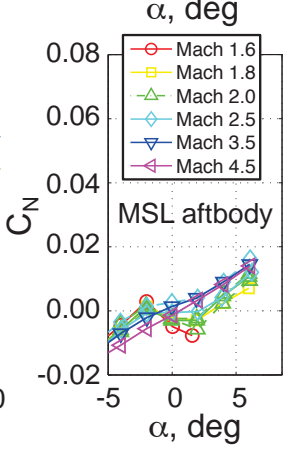

$\operatorname{Re}_{\infty}=1,2,3 \times 10^{6}$

Figure 7. Comparison of $C_{A}$ and $C_{N}$ data for a $70^{\circ}$ forebody.

\section{B. Force and Moment Data Trends}

Trends in force and moment coefficient data $\left(C_{A}, C_{N}, C_{D}, C_{L}, C_{m}, C_{n}, L / D\right)$ with angle of attack and sideslip are explored for different forebody geometries, different numbers of tabs, and different tab parameters. All moment coefficients, unless otherwise noted, are referenced to the model nose. A negative $C_{m}$ slope and a positive $C_{n}$ slope indicate that a given configuration is statically stable. Figure 8 shows the effect of varying forebody geometry on force and moment coefficients as a function of angle of attack. Figure 9 shows the yawing moment coefficient as a function of sideslip angle for the configurations tested with two tabs. No static instabilities are apparent in the force and moment coefficient trends for any of the trim tab configurations across the conditions tested with the moment reference point located at the nose. However, for moments taken about a more realistic CG location, e.g. $x_{C G} / D=0.30, z_{C G} / D=0.0$ ), the pitching moment slope becomes less negative for all configurations. In addition, the slope of $C_{m, C G}$ may change sign at small angles of attack for tab configurations with a $50^{\circ}$ or $60^{\circ}$ forebody and a trim tab canted into the flow (tab cant angle greater than that required to be perpendicular to the body axis).

Figure 10 shows the force and moment coefficient trends for all of the 1-tab configurations and the notab baseline configuration for the $70^{\circ}$ forebody at $M_{\infty}=4.5$. As expected, the addition of a trim tab shifts the $C_{m}$ curve "up", as compared to the no-tab baseline. The largest shift in $C_{m}$ occurs for the tabs with the greatest area $\left(6 \%\right.$, relative to the base area). Increasing the tab cant angle from parallel to the forebody $\left(0^{\circ}\right)$ to perpendicular to the body axis $\left(20^{\circ}, 30^{\circ}, 40^{\circ}\right.$, or $23^{\circ}$, depending on the forebody geometry) also increases 
$C_{m}$ across angles of attack from $-4^{\circ}$ to $+20^{\circ}$.
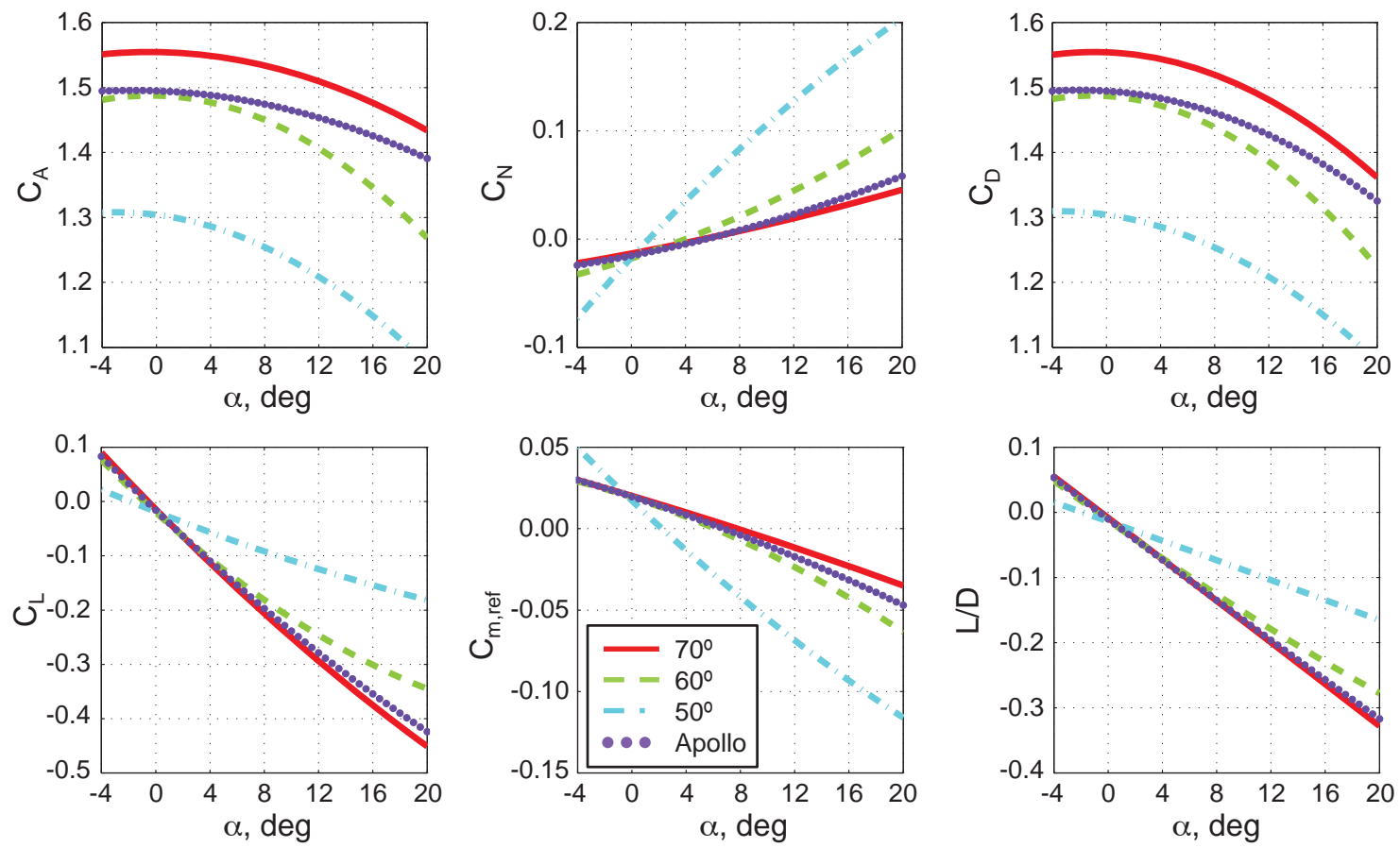

Figure 8. Force and moment trends for different forebodes with one tab ( $3 \%$ area, $2: 1$ aspect ratio, $0^{\circ}$ cant angle) at $M_{\infty}=4.5$.
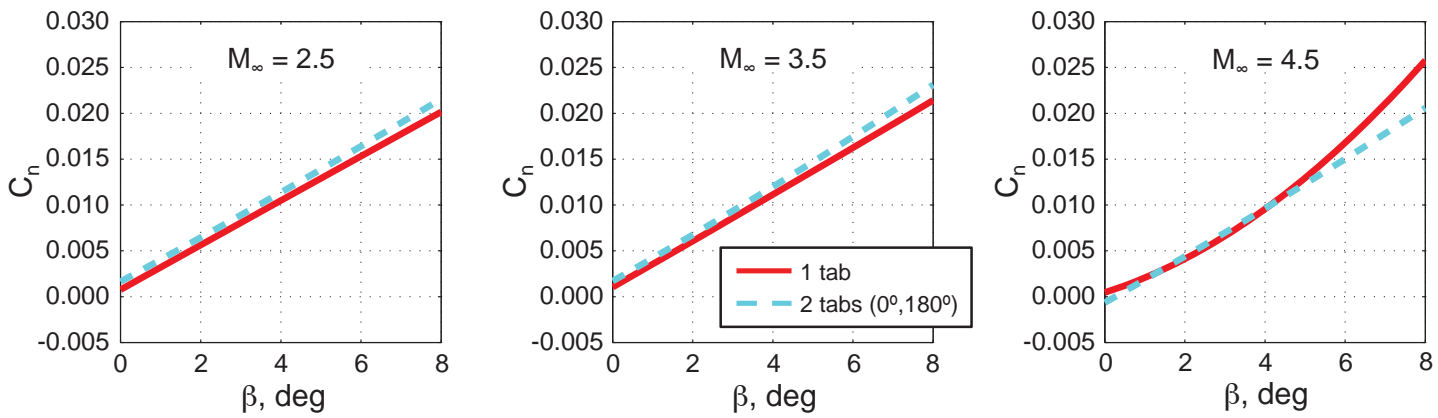

(a) $70^{\circ}$ forebody, $\alpha=16^{\circ}$, tab(s): $3 \%$ area, $2: 1$ aspect ratio, $20^{\circ}$ tab cant angle
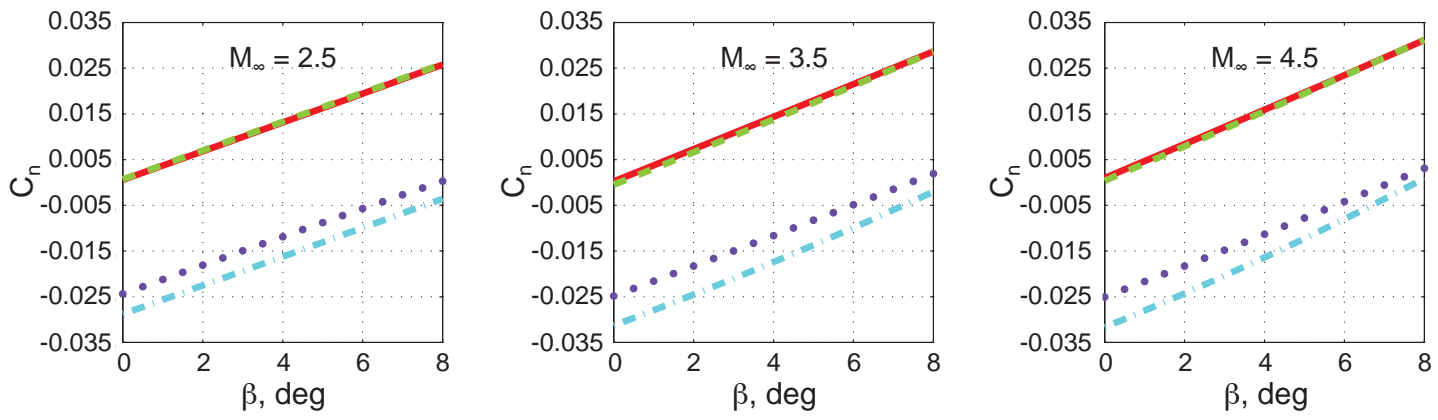

$$
\begin{array}{lll}
\hline \text { no tabs } & -\cdots & 2 \operatorname{tabs}\left(0^{\circ}, 90^{\circ}\right) \\
--1 \text { tab at } 0^{\circ} & \cdots & 2 \operatorname{tabs}\left(0^{\circ}, 120^{\circ}\right)
\end{array}
$$

(b) $60^{\circ}$ forebody, $\alpha=16^{\circ}$, tab(s): $3 \%$ area, $2: 1$ aspect ratio, $30^{\circ}$ tab cant angle

Figure 9. Yawing moment coefficient as a function of $\beta$ for configurations with two tabs. 

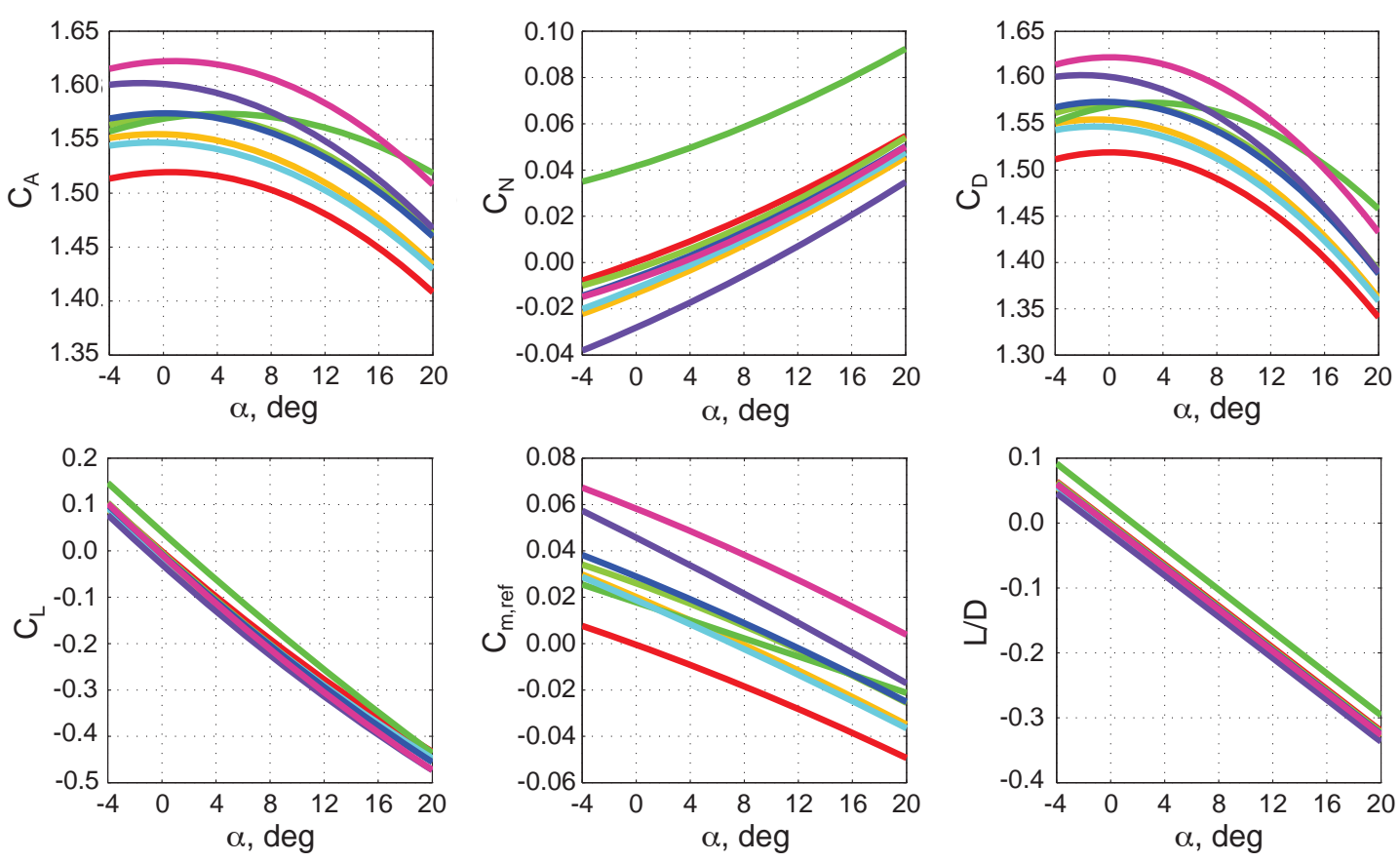

\begin{tabular}{|ll|}
\hline no tabs & $-3 \%(1: 2) 0^{\circ}$ \\
3\% (2:1) $0^{\circ}$ & $-3 \%(1: 2) 20^{\circ}$ \\
3\% (2:1) 20으 & $-6 \%(1: 1) 0^{\circ}$ \\
$-3 \%(2: 1) 90^{\circ}$ & $-6 \%(1: 1) 20^{\circ}$ \\
\hline
\end{tabular}

Figure 10. Trim tab effects on force and moment coefficients for the $70^{\circ}$ forebody at $M_{\infty}=4.5$.

Of the three tab parameters, changing the tab aspect ratio has the smallest effect. With the exception of the $90^{\circ}$ canted tab, varying trim tab configuration shifts the magnitude of force and moment coefficients with minimal change to the shape of the overall trends with angle of attack. In contrast, the $90^{\circ}$ canted tab imparts a normal force contribution that is significantly greater than that of the other trim tabs, resulting in slope variations of force and moment coefficients with angle of attack that are, in general, smaller than those for the trim tab configurations with smaller tab cant angles.

\section{Aerodynamic Trim Characteristics}

Trim characteristics $\left(\alpha_{\text {trim }},(L / D)_{\text {trim }}\right)$ are calculated for each of the trim tab configurations as a function of axial CG location $\left(x_{C G} / D=0.20\right.$ to 0.35$)$, assuming no radial CG offset $\left(z_{C G} / D=0\right)$. Trim tab effectiveness is quantified by calculating the radial CG offset required to achieve the same $L / D$ with no trim tab for each of the four forebody shapes. In all cases, any contribution to the CG location from the mass of the trim tab is neglected. All angles of attack beyond $20^{\circ}$ are extrapolated from the test data using the quadratic curve fits described previously in Section III.

Figure 11 shows $(L / D)_{\text {trim }}$ and the required radial CG offset to achieve the same $L / D$ with no trim tab for the $70^{\circ}$ forebody at $M_{\infty}=4.5$ as a function of axial CG location. The solid line is the $L / D$ for MSL at $M_{\infty}$ $=4.5$, and the shaded region indicates where data have been extrapolated (as a result of $\alpha_{\text {trim }}$ exceeding $\left.20^{\circ}\right)$. MSL's trim performance at these conditions $\left(M_{\infty}=4.5,(L / D)_{\text {trim }} \approx-0.29\right)$ can be matched using a $6 \%$ tab with a $0^{\circ}$ cant angle or a smaller tab with a non-zero cant angle. Across all of the forebody geometries and trim tab configurations tested, it is observed that larger tabs are more effective than smaller tabs, increasing tab cant angle also increases tab effectiveness, and varying tab aspect ratio has a minimal effect on the body's aerodynamic trim characteristics. Aerodynamic trim characteristics for each configuration at $M_{\infty}=4.5$ were given previously in Table 2 (see Section II), assuming $x_{C G} / D=0.291$ and $z_{C G} / D=0.0$.

Figure 12 shows the variation of the trends shown in Fig. 11 with Mach number. The largest variations are for the 3\% (2:1) $90^{\circ}$ and 6\% (1:1) canted tab configurations. Variations in trim characteristics and trim tab effectiveness with Mach number are dependent on the forebody geometry. Consistent across all forebody 
geometries, however, is the observation of the greatest variation in trim characteristics with $M_{\infty}$ to be for configurations with non-zero tab cant angles. For a given tab area and aspect ratio, a tab with a nonzero cant angle is more effective than the same tab with no cant angle. It is not unexpected, then, that as a vehicle's aerodynamic characteristics with no trim tab change as $M_{\infty}$ increases from 2.5 to 4.5 , tab configurations with non-zero cant angles exhibit greater variation with Mach number.
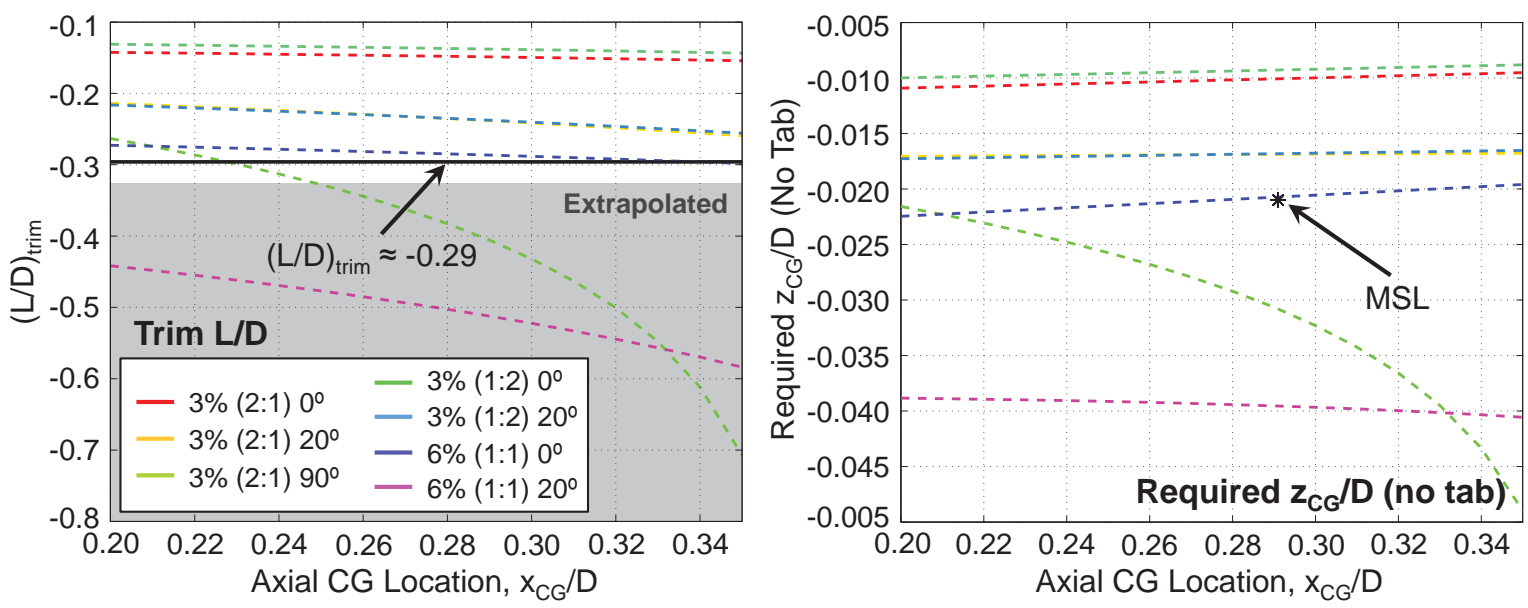

Figure 11. Trim characteristics for the $70^{\circ}$ forebody at $M_{\infty}=4.5$.
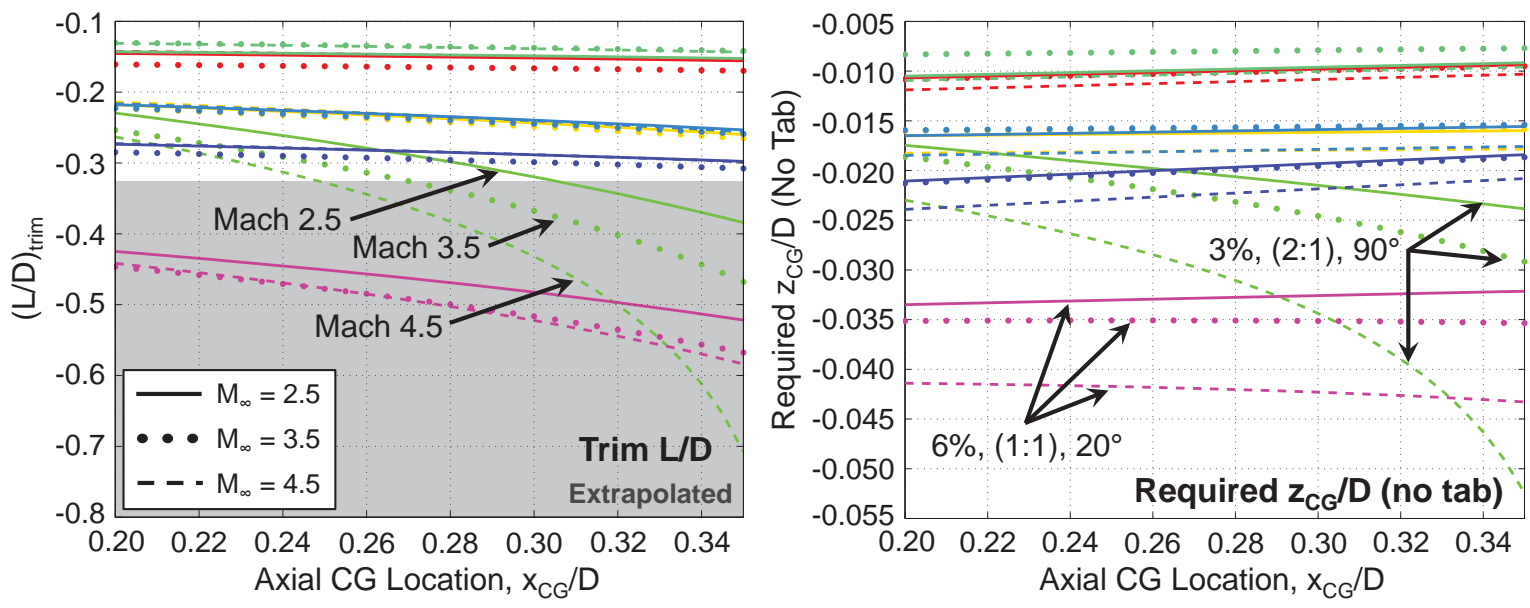

Figure 12. Variation in trim tab effectiveness for the $70^{\circ}$ forebody (same legend as for Fig. 11).

\section{Tab Parameter Significance}

The trim characteristics calculated for each configuration are then used to examine the relative significance of tab area, tab aspect ratio, and tab cant angle. While the test matrix does not allow for the effects of tab area, tab cant angle, and tab aspect ratio to be fully decoupled, a number of pairwise comparisons are available to illustrate the relative significance of the different tab parameters. Assuming no radial CG offset for the configurations with trim tabs, $\Delta(L / D)_{\text {trim }}$ is equal to the difference between $(L / D)_{\text {trim }}$ for the two configurations being compared. Figure 13a shows $(L / D)_{\text {trim }}$ as a function of axial CG location for six tab configurations with a $70^{\circ}$ forebody geometry. Figure $13 \mathrm{~b}$ shows the difference between pairs of curves in Fig. 13a as $\Delta(L / D)_{\text {trim }}$.

The order of the curves in Fig. 13b illustrates both the relative significance of different tab parameters and the inability to fully decouple the tab parameters based on the T1875 test matrix. The significance of 
the different tab parameters increases as $\Delta(L / D)_{\text {trim }}$ becomes increasingly negative. Figures 13a and 13b both show tab aspect ratio (as tested, with $3 \%$ area tabs) to have a minimal effect on $(L / D)_{\text {trim }}$. Tab area and tab cant angle are both significant. Tab area cannot be decoupled from tab aspect ratio, and the effect of tab area increases for non-zero tab cant angles. Similarly, the effect of tab cant angle is greatest for the largest $(6 \%)$ area tabs. The effects of tab area and tab cant angle are most significant across the parameters considered, and additional variation with $M_{\infty}$ is observed. While not included here, the same comparisons have been made to explore the effect of different tab parameters on $\Delta C_{m, r e f}$ with similar results. On the basis of these results, Section $\mathrm{V}$ is concerned with the performance of trim tabs with different tab areas and tab cant angles.

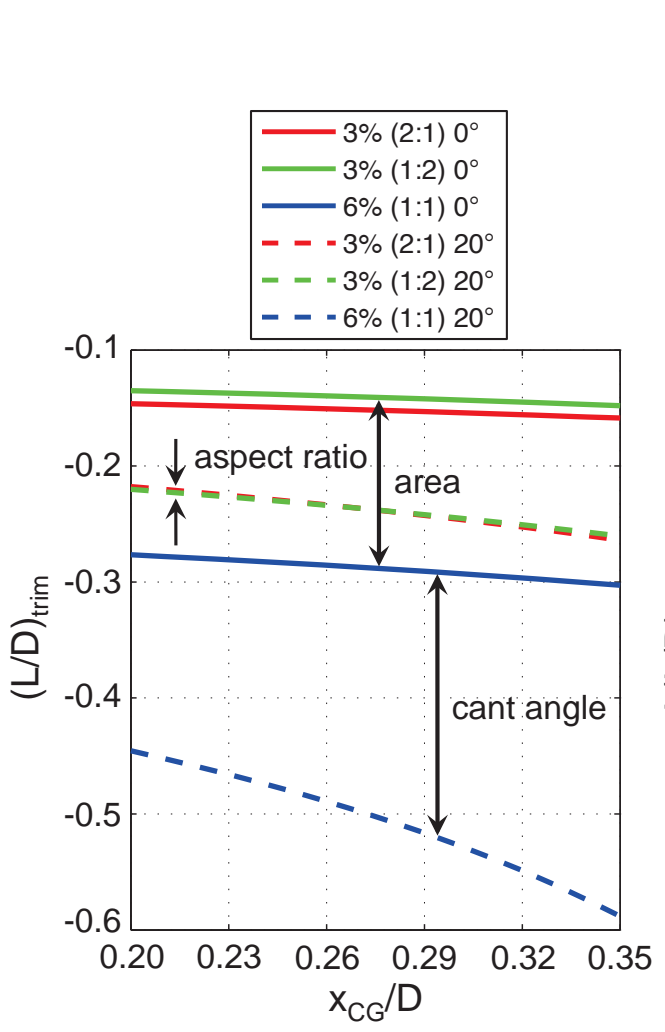

(a)

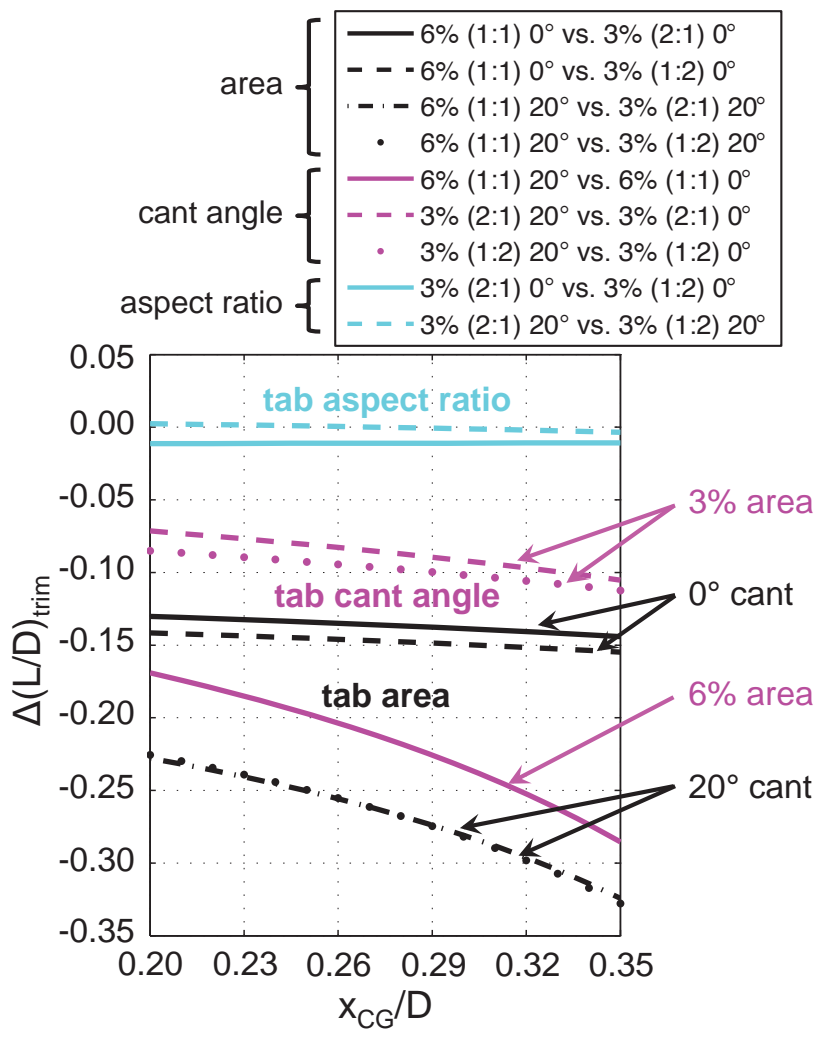

(b)

Figure 13. Relative significance of tab area, tab cant angle, and tab aspect ratio for the $70^{\circ}$ forebody at $M_{\infty}=4.5$.

\section{E. Relationship of Tab Area to Tab Performance}

Increments, or comparisons against the 0-tab baseline configurations, are used to investigate the relationship between trim tab area and tab performance. Figure 14a shows the relationship between $\Delta C_{m, r e f}$ and tab area for the $70^{\circ}$ forebody geometry and a $20^{\circ}$ canted tab. Both axes are normalized by the corresponding value for the smallest area tab configuration tested. In Fig. 14a, $\Delta C_{m}$ is normalized by the increment in $C_{m}$ for the $3 \%$ area tab. The normalization allows for comparison of the test data with a line having a slope equal to one (i.e. a one-to-one relationship). For each $M_{\infty}$ condition in Fig. 14, the data (interpolated) are above the dashed line, indicating that doubling the tab area increases $\Delta C_{m, \text { ref }}$ by more than a factor of two. Note, however, that no configurations were tested in which the moment arm was held constant and the tab area changed. Tab area and tab aspect ratio are coupled, and the $6 \%$ area tabs have twice the area as well as longer moment arms as compared to the 3\% area tabs. The slope of the interpolated test data varies with $M_{\infty}$ and also forebody geometry. Figure 14b shows the same relationship between $\Delta C_{m, r e f}$ and tab area for the $60^{\circ}$ forebody geometry and a $30^{\circ}$ canted tab. In Fig. 14b, the slope of the data and the position relative to the dashed line vary with increasing $M_{\infty}$. Additional testing at higher Mach numbers $\left(M_{\infty}>\right.$ 4.5) is needed to resolve differences in variation of trim tab performance with $M_{\infty}$ across the different fore- 
body geometries. Computational aerodynamic analysis of these configurations is recommended to further understand the relationship between tab area and tab performance. In particular, such analyses would be useful in exploring why doubling the tab area was found to be more effective for a $70^{\circ}$ sphere-cone than it was for a $60^{\circ}$ sphere-cone at $M_{\infty}=2.5$.
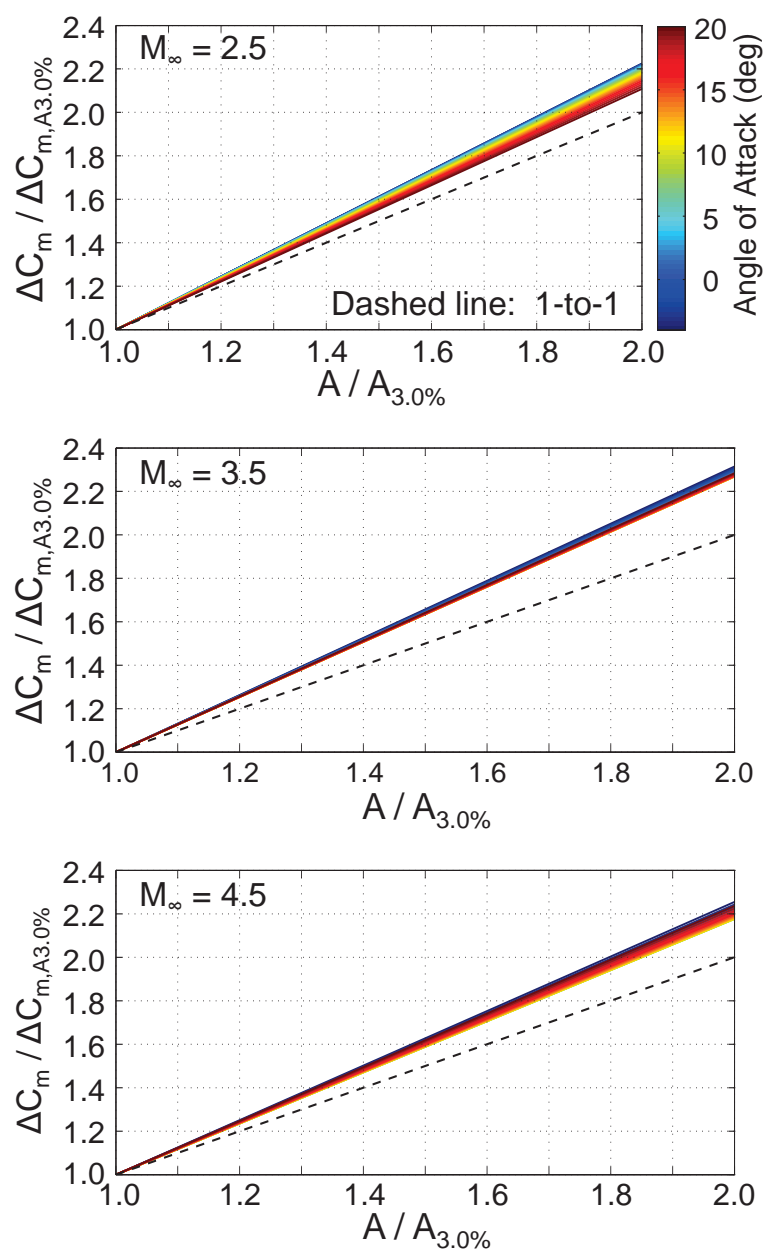

(a) $70^{\circ}$ forebody with $20^{\circ}$ canted tab
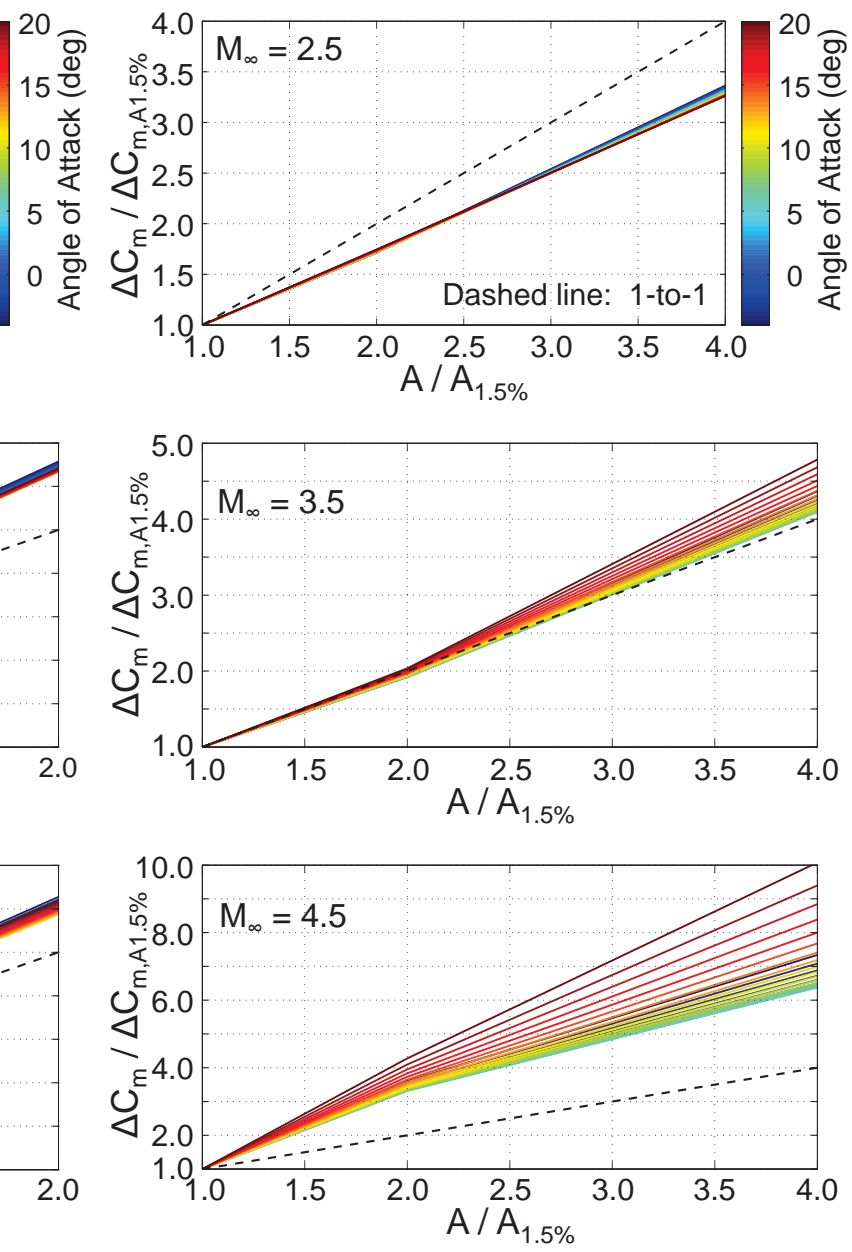

(b) $60^{\circ}$ forebody with $30^{\circ}$ canted tab

Figure 14. Relationship between $\Delta C_{m}$, ref and tab area for the $70^{\circ}$ forebody geometry with a $20^{\circ}$ canted tab and for the $60^{\circ}$ forebody geometry with a $30^{\circ}$ canted tab.

\section{Design Implications}

\section{A. Trim Tab Area}

For each forebody geometry and $M_{\infty}$ condition, estimates of the tab area required to achieve an $L / D$ ranging from -0.05 to -0.40 are made using the tab areas tested. Tab area estimates are also made for an $L / D$ of approximately - 0.29 (MSL $L / D$ at Mach 4.5) and an $L / D$ of -0.10 (sample flight test target). Figure 15 shows the relationship between $(L / D)_{\text {trim }}$ and tab area for the $70^{\circ}$ forebody geometry at $M_{\infty}=4.5$, assuming the tab has a 2:1 aspect ratio and $20^{\circ}$ cant angle. All shaded portions of Fig. 15 are regions where extrapolation of the test data was required as a result of $\alpha_{\text {trim }}$ exceeding $20^{\circ}$ (maximum $\alpha$ tested) or tab area exceeding $6 \%$ (maximum tab area tested). All other regions are interpolated from the no-tab baseline configuration and the $3 \%$ and $6 \%$ area tabs tested. Table 3 provides the estimated tab areas required to achieve $L / D=$ -0.29 and $L / D=-0.10$ for each forebody geometry and two different tab cant angles (parallel to the forebody and perpendicular to the body axis) at $M_{\infty}=4.5$. 


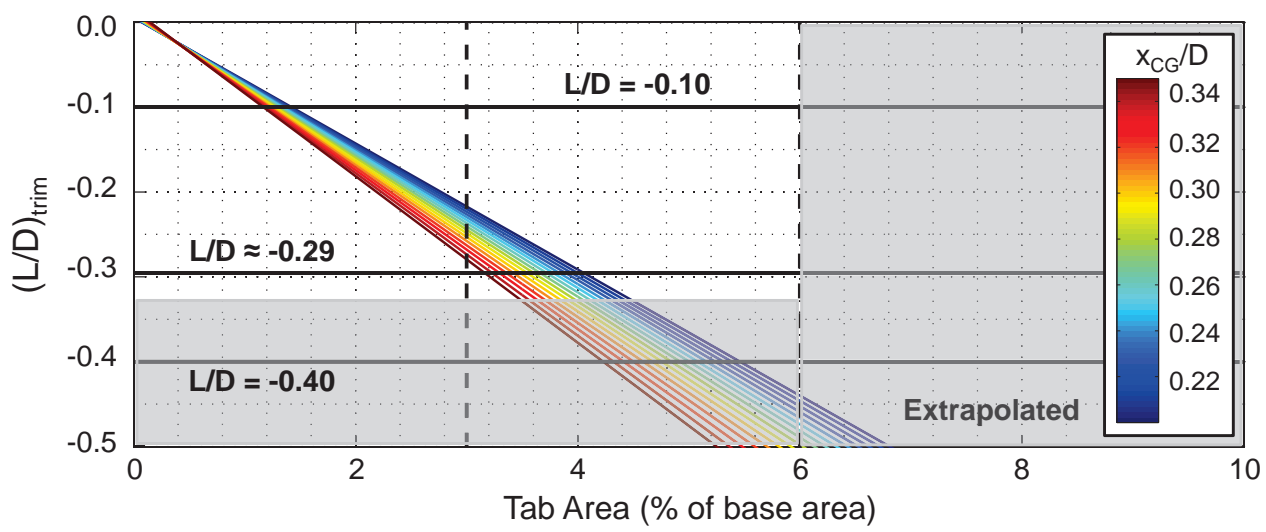

Figure 15. $(L / D)_{\text {trim }}$ as a function of tab area for the $70^{\circ}$ forebody geometry at $M_{\infty}=4.5$ with a $2: 1$ tab aspect ratio and a $20^{\circ}$ tab cant angle. Vertical dashed lines indicate tab areas tested in T1875.

Table 3. Estimated tab areas (as \% of base area) for $M_{\infty}=4.5$ conditions $\left(x_{C G} / D=0.291\right)$.

\begin{tabular}{lcccccccc}
\hline \hline Forebody & \multicolumn{2}{c}{$70^{\circ}$} & \multicolumn{2}{c}{$60^{\circ}$} & \multicolumn{2}{c}{$50^{\circ}$} & \multicolumn{2}{c}{ Apollo } \\
Tab Cant Angle & $0^{\circ}$ & $20^{\circ}$ & $0^{\circ}$ & $30^{\circ}$ & $0^{\circ}$ & $40^{\circ}$ & $0^{\circ}$ & $23^{\circ}$ \\
\hline$L / D=-0.10$ & $2.1 \%$ & $1.3 \%$ & $2.7 \%$ & $1.3 \%$ & $8.4 \%$ & $2.8 \%$ & $2.5 \%$ & $1.3 \%$ \\
$L / D=-0.29$ & $6.1 \%$ & $3.6 \%$ & $9.3 \%$ & $4.5 \%$ & $25.8 \%$ & $8.5 \%$ & $8.0 \%$ & $4.5 \%$ \\
\hline \hline
\end{tabular}

From Table 3, non-zero tab cant angles significantly reduce the required tab area to achieve a given $L / D$. Additionally, $0^{\circ}$ canted tabs may be prohibitively large for flight application. Variation with $M_{\infty}$ and axial CG location are observed for forebody geometry and tab cant angle, and the required tab area is more sensitive to axial CG location for non-zero tab cant angles.

\section{B. Trim Tab Cant Angle}

Tabs with non-zero cant angles trim at higher $L / D$ than $0^{\circ}$ canted tabs. Analogously, increasing tab cant angle reduces the tab area required to achieve a given $L / D$. Variation in tab cant angle may be useful in modulating $L / D$, though too few cant angles have been tested to estimate the highest performing tab cant angle for each configuration. The $60^{\circ}$ forebody geometry was tested with four tab cant angles $\left(0^{\circ}, 30^{\circ}, 60^{\circ}\right.$, $90^{\circ}$ ), and the data suggest an intermediate tab cant angle may provide maximum $L / D$ performance. Figure 16a shows $(L / D)_{\text {trim }}$ for each tab cant angle assuming no radial CG offset with notional curve fits through each set of data points.

Figure $16 \mathrm{~b}$ shows an estimate of the ratio of entry ballast mass to entry mass required to achieve the same performance as a canted trim tab for the $60^{\circ}$ forebody geometry. The ballast mass is assumed to be located at $85 \%$ of the forebody radius to produce the required radial CG offset for a $4.5 \mathrm{~m}$-diameter vehicle with an entry mass of $3300 \mathrm{~kg}$. The entry mass does not include any required cruise stage ballast mass or any effect from the mass of the trim tab.

Figure 17 shows the analogous trends for the $70^{\circ}$ forebody geometry. The MSL entry ballast mass was $174 \mathrm{~kg}$ (equal to the mass of one Mars Exploration Rover), resulting in a ratio of entry ballast to entry mass of approximately $5.3 \%$. The same performance $(L / D=-0.29)$ is achievable with an approximately $35^{\circ}$ tab cant angle with a 3\% area tab. Across all forebody geometries and $M_{\infty}$ conditions tested, a large variation in $(L / D)_{\text {trim }}$ is observed for small changes in tab cant angle. For example, increasing tab cant angle from $0^{\circ}$ to $20^{\circ}$ for the $70^{\circ}$ forebody ( $3 \%$ area tab) increases $(L / D)_{\text {trim }}$ from -0.15 to -0.24 . 


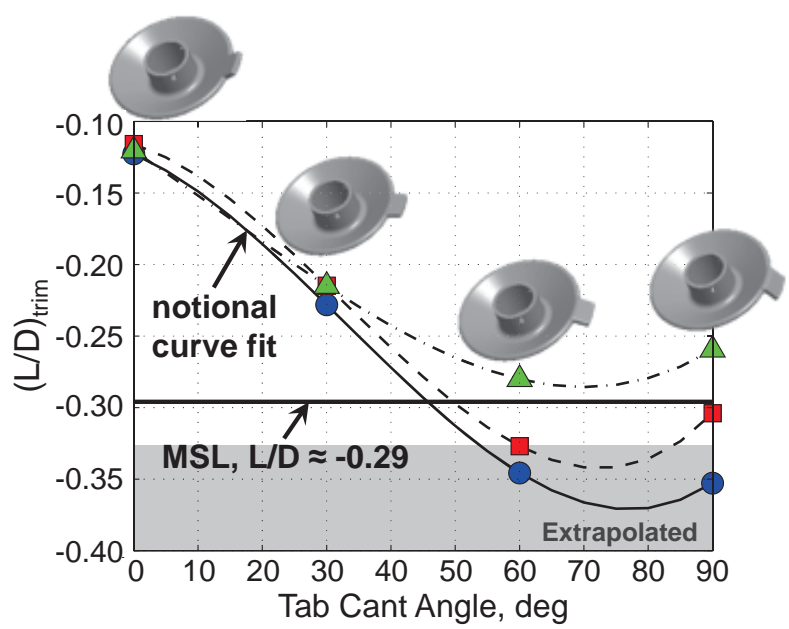

(a)

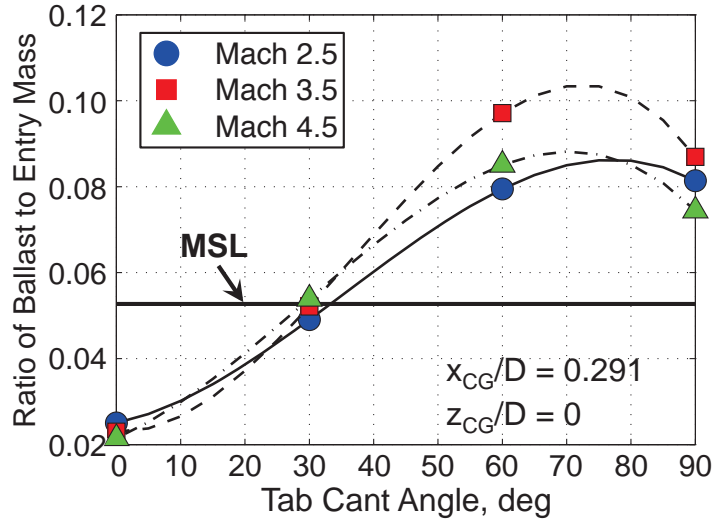

(b)

Figure 16. Tab cant angle performance for the $60^{\circ}$ forebody geometry ( $3 \%$ tab area, $2: 1$ tab aspect ratio).

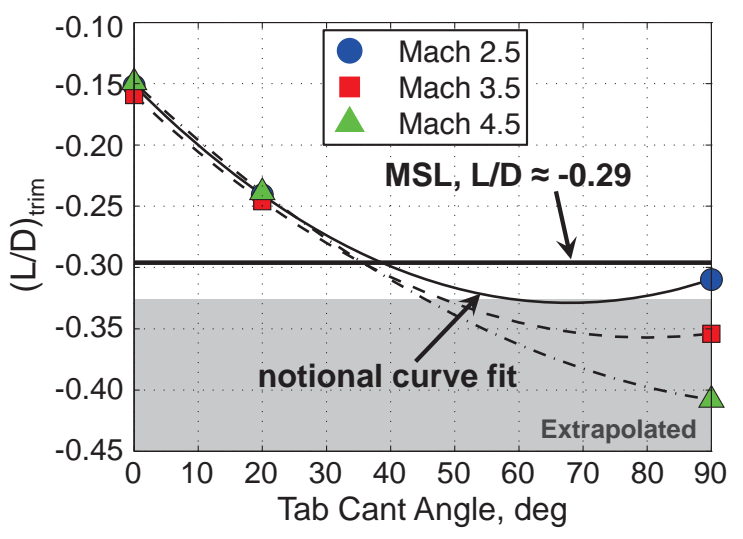

(a)

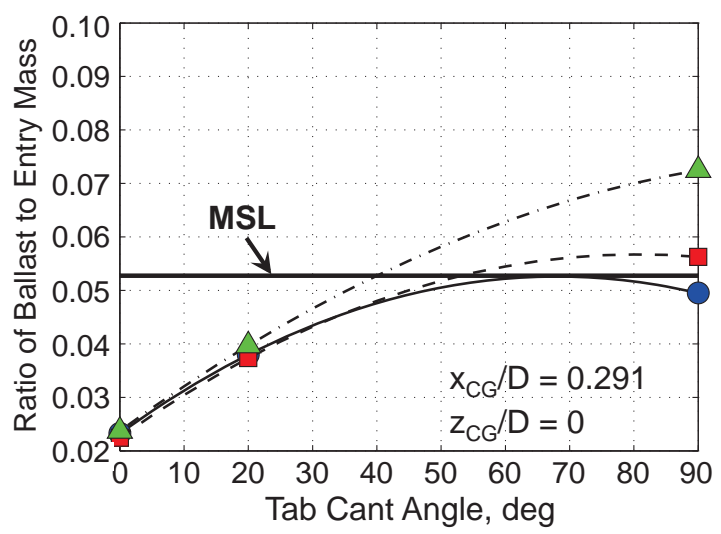

(b)

Figure 17. Tab cant angle performance for the $70^{\circ}$ forebody geometry ( $3 \%$ tab area, $2: 1$ tab aspect ratio).

\section{Conclusion}

Force and moment testing of 38 unique trim tab configurations was completed in May 2012 in the NASA Langley Research Center Unitary Plan Wind Tunnel. Testing was completed at Mach numbers of 2.5, 3.5, and 4.5 with $R e_{\infty}=1 \times 10^{6}$, spanning angles of attack from $-4^{\circ}$ to $+20^{\circ}$ and sideslip angles from $0^{\circ}$ to $+8^{\circ}$. Four forebody geometries were used: $70^{\circ}, 60^{\circ}$, and $50^{\circ}$ sphere-cones and Apollo. Tab parameters investigated were number of tabs $(0,1,2)$, tab area $(1.5 \%$ to $6 \%$, relative to model base area), tab cant angle $\left(0^{\circ}\right.$ to $\left.90^{\circ}\right)$, and tab aspect ratio $(2: 1,1: 2,1: 1)$.

The most significant tab parameters affecting tab performance were found to be tab cant angle and tab area. It was observed that increasing tab cant angle significantly reduced the tab area required to achieve a given $L / D$. Variations in the aerodynamics of the tab configurations were observed with $M_{\infty}$ and forebody geometry for Mach 2.5 to Mach 4.5. A $70^{\circ}$ sphere-cone forebody with a 3\% area tab and an approximately $35^{\circ}$ tab cant angle yielded similar aerodynamic performance to the Mars Science Laboratory entry vehicle using no radial center of gravity offset from ballast.

Additional work is required to support the construction of aerodynamic databases for blunt body entry vehicles with trim tabs. Testing at higher Mach numbers $\left(M_{\infty}>4.5\right)$ is needed to extend the experimental database and to provide aerothermal data. Aerothermal data is required to address the challenges of a tab with low thermal mass exposed to high heating. Computational analysis of the trim tab configura- 
tions examined here will further support aerodynamic database development and establish the capability to predict trim tab aerodynamic performance. With the development of aerodynamic databases for trim tab configurations, preliminary sizing analyses and generation of mass models for trim tabs will support higher-fidelity evaluation of system-level performance. The maturation of trim tabs will provide a flightviable system for satisfying aerodynamic performance requirements of atmospheric entry missions with comparably less mass than would be required to achieve similar performance using ballast.

\section{Acknowledgments}

The authors would like to thank the NASA LaRC UPWT team and to acknowledge support of this work by the NASA Hypersonic Inflatable Aerodynamic Decelerator (HIAD) Project.

\section{References}

${ }^{1}$ Lockwood, M. K., Powell, R. W., Sutton, K., Prabhu, R. K., Graves, C. A., Epp, C. D., and Carman, G. L., “Entry Configurations and Performance Comparisons for the Mars Smart Lander," Journal of Spacecraft and Rockets, Vol. 43, No. 2, 2006, pp. $258-269$.

2"Viking '79 Rover Study Volume 1: Summary Report," NASA CR-132417, 1974.

${ }^{3}$ Edquist, K. T., "Computations of Viking Lander Capsule Hypersonic Aerodynamics with Comparisons to Ground and Flight Data," AIAA 2006-6137, 2006.

${ }^{4}$ Schoenenberger, M., Dyakonov, A. A., Buning, P. G., Scallion, W., and Van Norman, J. W., “Aerodynamic Challenges for the Mars Science Laboratory Entry, Descent and Landing," AIAA 2009-3914, 2009.

${ }^{5}$ Horvath, T. J., O'Connell, T. F., Cheatwood, F. M., Alter, S. J., and Prabhu, R. K., “Experimental Hypersonic Aerodynamic Characteristics of the 2001 Mars Surveyor Precision Lander with Flap," AIAA 2002-4408, 2002.

${ }^{6}$ Ivanov, M. C., Blood, E. M., Cook, B. T., Giersch, L. R., Grover, M. R., Jakobowski, J. K., Rivellini, T. P., Su, R. P., Samareh, J. A., Zang, T. A., Winski, R. G., Olds, A. D., and Kinney, D. J., "Entry, Descent and Landing Systems Analysis Study: Phase 2 Report on Mars Science Laboratory Improvement," NASA/TM-2011-216988, 2011.

${ }^{7}$ Sammonds, R. I., and Dickey, R. R., "Effectiveness of Several Control Arrangements on a Mercury-Type Capsule," NASA TM X-579, 1961.

${ }^{8}$ Tendeland, T., and Pearson, Jr., B. D., "Effectiveness of Two Flap Controls on a Mercury Type Capsule at a Mach Number of 15 in the Ames Hypersonic Helium Tunnel," NASA TM X-660, 1962.

${ }^{9}$ Neal, Jr., L., "An Exploratory Investigation at a Mach Number of 6.9 into the Use of Aerodynamic Controls for Modulating the Lift-Drag Ratio of an Apollo Type Configuration," NASA TM X-816, 1963.

${ }^{10}$ Lockwood, M. K., Sutton, K., Prabhu, R. K., Powell, R. W., Graves, C. A., Epp, C. D., and Carman, G. L., “Entry Configurations and Performance Comparisons for the Mars Smart Lander," AIAA 2002-4407, 2002.

${ }^{11}$ Zang, T. A., Cianciolo, A. M., Ivanov, M. C., Sostaric, R. R., and Kinney, D. J., “Overview of the NASA Entry, Descent and Landing Systems Analysis Studies for Large Robotic-class Missions," AIAA 2011-7294, 2011.

${ }^{12}$ Winski, R. G., Garcia-Llama, E., Prakash, R., Shidner, J. D., Grover, M. R., and Ivanov, M. C., "Entry, Descent, and Landing Performance Trades to Increase Landed Mass for the Mars 2018 Mission,", IEEEAC Paper 1236, 2012.

${ }^{13}$ Murphy, K. J., Horvath, T. J., Erickson, G. E., and Green, J. M., “Supersonic Aerodynamic Characteristics of Proposed Mars ‘07 Smart Lander Configurations," AIAA 2002-4409, 2002.

${ }^{14}$ Edquist, K. T., Liechty, D. S., Hollis, B. R., and Alter, S. J., "Aeroheating Environments for a Mars Smart Lander," AIAA 20024505, 2002.

${ }^{15}$ Liechty, D. S., Hollis, B. R., and Edquist, K. T., “Control Surface and Afterbody Experimental Aeroheating for a Proposed Mars Smart Lander Aeroshell," AIAA 2002-4506, 2002.

${ }^{16}$ Murphy, K. J., Watkins, A. N., Korzun, A. M., and Edquist, K. T., "Testing of the Trim Tab Parametric Model in NASA Langley's Unitary Plan Wind Tunnel," AIAA Paper 2013-XXXX, 2013.

${ }^{17}$ Blake, W. W., “Experimental Aerodynamic Characteristics of the Viking Entry Vehicle Over the Mach Range 1.5 - 10.0," NASA CR-159225, 1971. 